\title{
Gender as a Moderator between Work-Family Conflict and Job Satisfaction of Medical Doctors: The Case of Ghana
}

\author{
Adjoa Afedua Nsaful ${ }^{*}{ }^{\circledR}$, Jichuan Sheng1, Emmanuel Nii Martey ${ }^{2}$ \\ ${ }^{1}$ School of Business, Nanjing University of Information Science \& Technology, Nanjing, China \\ ${ }^{2}$ University of Professional Studies, Accra, Ghana \\ Email: *afeduansaful@gmail.com, jsheng@nuist.edu.cn, enmmartey@gmail.com
}

How to cite this paper: Nsaful, A. A., Sheng, J. C., \& Martey, E. N. (2021). Gender as a Moderator between Work-Family Conflict and Job Satisfaction of Medical Doctors: The Case of Ghana. Journal of Human Resource and Sustainability Studies, 9, 193-211.

https://doi.org/10.4236/jhrss.2021.92013

Received: March 9, 2021

Accepted: April 25, 2021

Published: April 28, 2021

Copyright $\odot 2021$ by author(s) and Scientific Research Publishing Inc. This work is licensed under the Creative Commons Attribution International License (CC BY 4.0).

http://creativecommons.org/licenses/by/4.0/

\begin{abstract}
In recent times, during the outbreak of the novel COVID-19 pandemic, many health care workers, especially doctors, have to work long or irregular hours due to the increasing demand for health care services. Work and family have been prominent in an individual's life and require a great deal of time, energy and other resources to manage these multiple responsibilities. Worldwide studies have revealed that doctors have to deal with quite several extraneous difficult tasks in their day-to-day working environment resulting in a high percentage of doctors quitting this noble profession. However, there is a lack of evidence relating to the role of gender in this whole problem. Therefore, this assessed moderating role of gender between work-family conflict and job satisfaction in the case of Ghanaian doctors during the novel coronavirus era. A multi-stage sampling technique was employed to select three hundred and sixty-four (364) doctors for this study. A structured E-questionnaires was distributed using social media platform, mainly to collect data from study participants. Although, gender and work-family conflict were significantly related to job satisfaction, gender did not moderate the relationship between work-family conflict and job satisfaction. Therefore, this study recommends hospital management and policy makers consider ways of managing the autonomy, flexi-time, recognition, and working conditions of doctors to improve their job satisfaction during this pandemic and beyond.
\end{abstract}

\section{Keywords}

Work-Family Conflict, Job Satisfaction, Gender, COVID-19, Ghana Health Service 


\section{Introduction}

The discrepancy between employees' work and family demands has proven to be challenging in this $21^{\text {st }}$ century dynamic organizational environment. A plethora of studies have indicated that every profession, including those in the educational sectors, medical sectors, business financial sectors, and even domestic sectors, is susceptible to work and family associated crisis (Pfleiderer, Bortul, Palmisano, Rodde, \& Hasebrook, 2018; Opoku Mensah, Amissah, \& Nsaful, 2018; Zotorvie, Kudo, \& Adade, 2017; Pitney, Mazerolle, \& Pagnotta, 2011).

Job satisfaction is one of the three job attitudes exhibited by employees in an organization. It is believed to be an overly researched construct in the field of organizational behavior as it has demonstrated to influence several variables such as productivity, turnover, absenteeism, quality work-life (Martins, Tukur, Danburam, \& Salwau, 2016; de Oliveira Vasconcelos Filho, de Souza, Elias, \& D’Ávila Viana, 2016; Owolabi, 2015).

Doctors are essential workers and constitute great human resources for a country in times of an uncertainty and clinical complexity, such as the COVID-19 pandemic. Global concern has stipulated that doctors have to cope with numerous extraneous difficult tasks in their day-to-day working environment, resulting in many doctors resigning from this noble profession (WHO, 2017). A cordial doctor-patient relationship is of great significance in health care while a role confused doctor coupled with dissatisfaction on a job will be detrimental (Annor, 2016; Nataša et al., 2010). Over the years, Ghanaian doctors have encountered many plights in the professional facets ranging from medical technology, inadequate finances, and medical education (Adua, Frimpong, Li, \& Wang, 2017). During the recent times outbreak of the novel COVID-19 pandemic, many health care professionals, particularly, doctors have to work long hours due to the increasing request for health care services. As a result of the high demand, many countries have experienced a shortage of health care workers forcing most junior doctors to be working in new demanding roles (WHO, 2020).

Greenhaus and Beutel (1985) defined the concept of work-family on the multidimensional premises of time-based, strain-based, and behavior-based. For some time now, male and female duties have evolved; hence, men and women's the responsibilities have become more similar, making it obvious the dilemma of gender and work-family conflicts.

\subsection{Statement of the Problem}

Work and family are outstanding aspects of an individual's life and require a great deal of time, energy, and other resources to manage these responsibilities. Previous studies show that conflicts arise from both work and family spheres and leads to various consequences on the individual, family and organization (Opoku Mensah, Amissah, \& Nsaful, 2018; Erdamar \& Demirel, 2016; DarteyBaah, 2015). 
Though work-family conflict, when managed appropriately, can lead to significant outcomes such as job satisfaction, family satisfaction, family performance, work performance, marital satisfaction, and organizational commitment (Greenhaus, Ziegert, \& Allen, 2012), it does not erase the fact that medical doctors are at the front line of the increasing cases of the novel 2019 coronavirus which put them at risk of infection and consequently, putting their lives in danger. Other dangers include pathogen exposure, long working hours, occupational burnout, psychological distress, fatigue, and even death (Centers for Disease Control and Prevention, 2020).

This study will bridge the gap by adding up to the literature the multi-dimensionality of work-family conflicts connected with the rigid working time of Ghanaian medical doctors being call during odd hours to attend to emergencies. Rui (2017) stipulated that job satisfaction does not solely affect medical doctors' careers but can have a significant effect on the patients they attend to. In regards to the gap, various factors that can contribute or are determinants to doctors' overall job satisfaction or dissatisfaction such as degree of autonomy, the number of working hours, work intensity, salary, lack of recognition, working environment, communication and feedback and being married (Martins, Tukur, Danburam, \& Salwau, 2016; Fu, Sun, Wang et al., 2013; Ajayi, Bello, \& Asuzu, 2018). Concentrating on these gaps was the focus of this research. Lots of literature emphasizes the effects of work-family on the female and downplaying its effects on the male counterparts (Opoku Mensah, Amissah, \& Nsaful, 2018). The study looked at the final effect work-family conflict, and job satisfaction has on both male and female doctors in Ghanaian hospitals during this COVID-19 global crisis.

\subsection{Purpose of the Study}

The purpose is to assess the moderating role of gender between work-family conflict and job satisfaction in Ghanaian doctors' case during the novel coronavirus pandemic. To attain a successful and valid conclusion, the following objectives guided the study:

1) To examine the effect of work-family conflict (behavior-based, time-based, and strain-based) on job satisfaction among medical doctors in Ghana during the COVID-19 pandemic.

2) To measure the effect of work-family conflict on gender among these Ghanaian doctors.

3) To assess the effect of gender in moderating the relationship between work-family conflict and job satisfaction among these doctors.

\subsection{Research Questions}

The following research questions addressed the specific objectives of the study:

1) To what extent does work-family conflict influence medical doctors' job satisfaction during the COVID-19 pandemic in Ghana? 
2) What reasons account for the effect of work-family conflict on gender among medical doctors in Ghana?

3) What factors influence gender in moderating the relationship between work-family and job satisfaction among medical doctors in Ghana?

\subsection{Significance of the Study}

The study will provide a piece of empirical evidence from vital information to health (hospital) managements, policymakers, and individuals in academia. To the hospital management and policymakers in the country, the study's findings of the study will inform their strategic and policy decisions regarding the work-family conflict (WFC) and job satisfaction (JS) of doctors during any major pandemic that the country might have to face in the future.

Further, it will contribute to the growing literature on the variables of study (WFC, JS, and gender) for the individuals in academia. It will also serve as a basis for further studies in other areas in the health sectors that employees' welfare and attitudes aid their overall productivity.

\section{Literature}

\subsection{Work-Family Conflict}

Work-family conflict has opposing concerns for both staff members and management (Hamid \& Amin, 2014). According to Nawab and Iqbal (2013), workers encounter conflicts from work-related to distinct reasons of work stressors like limited authority, working hours and work overload. However, management should be deliberate to consider family-related needs due to their gender characteristics mainly; both sexes tend not to have significant differences in their encounter of work-family issues (Nasurdin, Ahmad, \& Zainal, 2013). Unreasonable job stress emanating from bad working conditions is considered one of the major components that cause work-family conflict (Jamadin et al., 2015). The work-family conflict phenomenon ascertains how commitment in one role can incapacitate the individual from performing another equally significant role in the individual's life (Kahn, Wolfe, Quinn, Snoek, \& Rosenthal, 1964). Some researchers who investigated work-family conflict clarify family role as the contention starting role and work as the contention tolerating role. In contrast, others suggest work to be the contention starting role and family to be the contention tolerating role depending on the researcher's analytic view. Carlson, Kacmar, and Williams (2000) elaborated on a dimensional measure of work-family conflict constructed to outline three main forms of work-family conflict (timebased, strain-based, and behavior-based). This study would concentrate on WFC's multidimensionality that would intend to add up to the scanty literature available. This study will consider the Role Theory (Katz and Kahn, 1978). The theory proposed that the assumption encompassing the various duties an individual performs can produce inter-role conflict when the contention to dominate the time the individual uses to satisfy all other demands for his or her work 
and family duties since each duty requires time, energy, and dedication.

\subsection{Job Satisfaction}

In present-day society, one of the essential measures to self-realization is getting a job. The satisfaction an individual is supposed to derive from the job is considered a key factor in achieving quality of life (Lent et al., 2011). In general, workers with higher job satisfaction are usually effective and enthusiastic towards their work, which benefits the organization in the long run (Coetzee \& Stoltz, 2015). According to WHO (2010), the African continent has confronted serious human resource deficiencies, which have brought about numerous nations' failure to begin and support reliable health services. It was revealed that the degree of autonomy was significantly related to job satisfaction (Martins et al., 2016). The current study seeks to examine the job satisfaction domain made up of recognition, the autonomy of work, number of working hours, working conditions, supervision and promotion that could facilitate doctors' work in their various health institutions. The Herzberg's two-factor theory can best explain job satisfaction in this current study. The Hygiene factors and the Motivator factors of these doctors under study.

\subsection{Gender}

Traditionally, the men and women's duties have whirled throughout the years; hence, their commitment and necessities have become comparable, making it evident the plight of work-family conflict. The Gender Perspective Theory postulates that, traditions and social settings an individual finds himself or herself tend to govern and determine their social obligations.

\subsection{Conceptual Framework}

Figure 1 illustrates the research model for this study by exploring the effect work-family conflict multidimensionality elements have on doctors' job satisfaction while testing the moderating role of gender.

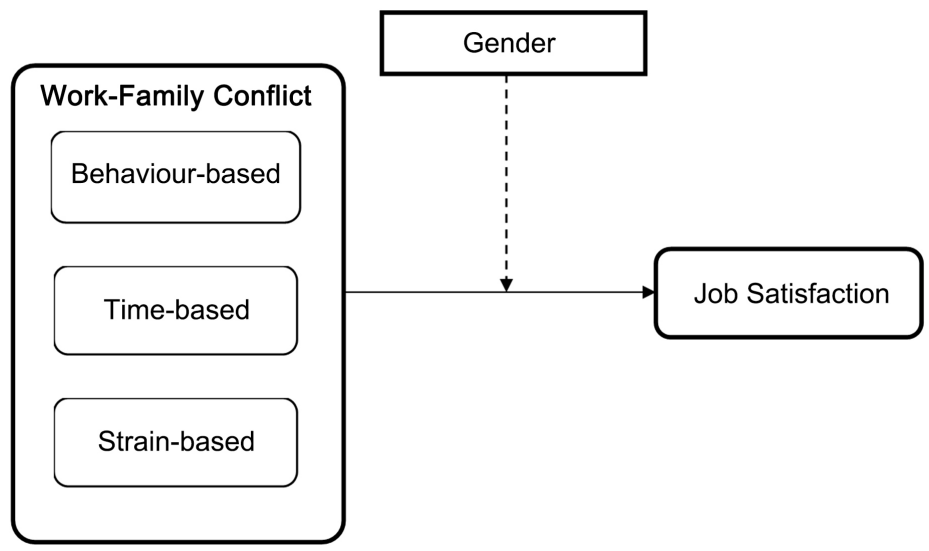

Figure 1. Relationship between the independent variable, dependent variable and moderated variable as hypothesized in this study (Author's Construct). 


\section{Hypothesis}

H1: Work-family conflict will negatively affect job satisfaction.

H1a: Behaviour-based (B-B) will negatively influence job satisfaction.

H1b: Time-based (T-B) will negatively influence job satisfaction.

H1c: Strain-based (S-B) will negatively influence job satisfaction.

$\mathrm{H} 2$ : Work-family will negatively affect gender.

H2a: WFC will negatively affect female doctors.

H2b: WFC will positively affect male doctors.

H3: Gender does not moderate the relationship between work-family conflict and job satisfaction.

\section{Methodology}

Research design: The study followed a descriptive research design making use of the survey. The study relied on a quantitative approach from a positivist perspective that emphasizes on logic, truth, and realities. In the view of Ary, Jacobs, Irvine and Walker (2018), the descriptive research design offers a more concise and concrete image of events and attempts to clarify the understanding and actions of individuals based on data obtained at every given moment.

Population: According to Aetna International, the country has over 1300 and 1800 private and public health facilities, respectively, as of 2019. Statistics from the Ghana Health Service showed a total of 4016 doctors in the country as of 2017. Greater Accra, Ashanti Regions, and Eastern had the highest distribution of doctors, respectively. Malhotra and Peterson (2006) observe that the target population is the group of components or the objects that secure the information that the analyst looks for. Due to the inaccessible current data on the number of doctors in the country, the target population of 4016 doctors is used for the study. As such, both male and female doctors were sampled for the study.

Sample and Sampling Procedure: The Yamane (1967) formula was used to determine the sample size for the study. The sample size is calculated as

$$
\begin{gathered}
n=\frac{N}{1+N(e)^{2}} \\
n=\frac{4016}{1+4061(0.05)^{2}}=364
\end{gathered}
$$

where $n$ is the sample and $N$ denotes population; $e$ is the error margin.

A multi-stage (stratified, convenience and snowball) sampling technique was employed to select 364 doctors for this study.

Data and Data Collection Instruments: Considering the financial and health implications associated with the physical collection of data from respondents around this pandemic era, an electronic method was utilized to collect data for the study. E-questionnaires were designed using google form and distributed using social media platforms, mainly WhatsApp. Questionnaire items that measured WFC and job satisfaction were measured on a five-point Likert scale with respondents indicating their degree of agreement or disagreement to each 
statement on a scale of 1 - 5 where 1-Strongly Disagree, 2-Disagree, 3-Neutral, 4-Agree, 5-Strongly Agree. These sections of the questionnaire were made up of close and open-ended questionnaires adapted from literature.

The following instruments were used to collect the data for the study:

Section B, Job satisfaction was measured using Herzberg's two-factor theory (Hygiene and Motivator factors). It is a 6-item instrument which assessed key hygiene and motivator factor relevant for this study.

Hygiene factors included; working condition, supervision, working hours.

Motivator factors included; recognition, autonomy and promotion.

Section C, Work-family conflict construct was measured by adapting the short valid, predictive measure of work-family conflict by Matthews, Kath, and Barnes-Farrell (2010). It is a 12-item instrument that assessed key time-based, strain-based and behavior-based conflict construct relevant for this study. Questions that elicit response include:

Time-based conflict, for example, my job keeps me from doing family activities more than I would like.

Strain-based conflict, for example, I am completely exhausted from doing anything by the time I get home from work.

Behavior-based conflict, for example, the problem-solving behaviors I use in my job are not effective in resolving problems at home.

Validity and Reliability of Instrument: Testing for the validity and reliability of the instrument used is required for an effective and efficient study. The Cronbach's alpha reliability method was employed for the estimation of the overall value of the questionnaire as shown in Table 1 below.

According to Pallant (2010), a reliability coefficient of 0.7 and above is acceptable. However, a generally accepted rule is that $\alpha$ of $0.6-0.7$ indicates an acceptable level of reliability (Ursachi, Horodnic, \& Zait, 2015). This means that internal constituents had a significant correlation with one other.

Additionally, pilot test was carried out using fifty (50) medical practitioners before administering the questionnaire to the sample of the study. The pilot testing guarantees the reliability of the questionnaire by measuring the items of a specific variable.

The fieldwork took place over a period of 4 months between $1^{\text {st }}$ September to $1^{\text {st }}$ January 2021.

Data Analysis: Data collected was analyzed with regression analysis using the statistical package for social sciences version 26 (SPSS) as the main statistical tool. Proportions, frequencies, and regression analysis were employed in the analysis of this study.

\section{Results}

From Table 2, three hundred and sixty-four (364) doctors participated in the study; out of this $54.67 \%$ were females. The age group of 26 - 35 years constituted the majority of the respondents age representing $67.31 \%(34.62 \%+32.69 \%)$. 
Table 1. Reliability statistics.

\begin{tabular}{ccc}
\hline Construct & Item & Cronbach's Alpha \\
\hline Job Satisfaction & 6 & 0.812 \\
Time-Based & 4 & 0.853 \\
Strain-Based & 4 & 0.781 \\
Behaviour-Based & 4 & 0.628 \\
Work-Family Conflict & 12 & 0.827 \\
\hline
\end{tabular}

Table 2. Demographic characteristics of respondents.

\begin{tabular}{|c|c|c|c|}
\hline Variable & Description & Frequency (n) & Percentage \\
\hline \multirow{2}{*}{ Gender } & Male & 165 & 45.33 \\
\hline & Female & 199 & 54.67 \\
\hline \multirow{5}{*}{ Age } & $20-25$ & 21 & 5.77 \\
\hline & $26-30$ & 119 & 32.69 \\
\hline & $31-35$ & 126 & 34.62 \\
\hline & $36-40$ & 38 & 10.44 \\
\hline & $40-45$ & 60 & 16.48 \\
\hline \multirow{2}{*}{ Marital Status } & Single & 166 & 45.60 \\
\hline & Married & 198 & 54.40 \\
\hline \multirow{2}{*}{ Dependents } & Yes & 201 & 55.22 \\
\hline & No & 163 & 44.78 \\
\hline \multirow{3}{*}{ Education } & Bachelor's Degree & 198 & 54.40 \\
\hline & Masters & 69 & 18.96 \\
\hline & Fellowship & 97 & 26.65 \\
\hline \multirow{8}{*}{ Clinical Department } & Anaesthesia & 29 & 7.97 \\
\hline & Dentistry & 30 & 8.24 \\
\hline & General Physician & 35 & 9.62 \\
\hline & General Practitioner & 162 & 44.51 \\
\hline & Gynaecology & 18 & 4.95 \\
\hline & Obstetrics & 21 & 5.77 \\
\hline & Paediatrics & 31 & 8.52 \\
\hline & Surgery & 38 & 10.44 \\
\hline \multirow{5}{*}{ Work Experience } & less than 1year & 21 & 5.77 \\
\hline & $1-3$ years & 153 & 42.03 \\
\hline & $4-6$ years & 96 & 26.37 \\
\hline & 7 - 9 years & 30 & 8.24 \\
\hline & 10 years above & 64 & 17.58 \\
\hline \multirow{2}{*}{ Night Shift } & Yes & 145 & 39.8 \\
\hline & No & 219 & 60.2 \\
\hline $\mathrm{N}=364$ & & & \\
\hline
\end{tabular}


More married (54.4\%) persons in the population were sampled than persons who were not married. A majority of the respondents, represented by 201 respondents were living with dependents as at the time of the study. Most of the doctors sampled were general practitioners. This constituted $44.5 \%$ of the respondents.

\section{Work-Family Conflict and Job Satisfaction}

H1: Work-family conflict will negatively affect job satisfaction.

The results in Table 3 show that WFC negatively affects job satisfaction. A unit increase in the WFC reduces job satisfaction by 0.238 . This is highly significant at one percent ( $p$-value $<0.001)$. The overall regression model is significant at a one percent level of significance with an F-statistic of 62.96. The R-square coefficient of determination, explains the variation in the dependent variable attributed to the independent variable. An R-square value of 0.15 suggests that $15 \%$ of job satisfaction variations (dependent variable) can be attributed to the work-family conflict (independent variable).

From Table 4, the findings suggest that Behaviour-based WFC, Strain-based WFC, and Strain-based WFC negatively and significantly affect doctors' job satisfaction. When doctors endure work-family conflicts emanating from behaviour, their job satisfaction is negatively impacted. Further, at a $5 \%$ significant level, a unit increase in doctors' time-based conflicts reduces job satisfaction of doctors by $0.22(\beta=-0.22)$. Additionally, a unit increase in strain-based conflicts reduce job satisfaction by $0.32(\beta=-0.325)$.

\section{Work Family Conflict and Gender}

The study also sought to investigate the relationship between work-family conflict and gender. The result is presented in Table 4.

From Table 5, female doctors are less likely $(\beta=-1.22)$ to be affected by work-family-conflict compared to males on average. This is significant at a $5 \%$ level of significance ( $p$-value $<0.05)$. The $\mathrm{R}$ square value suggested that the gender (females) explains $1.5 \%$ of WFC variations. Overall, the model is significant at a $5 \%$ level of significance $(\mathrm{F}=5.42, p$-value $<0.05)$.

Table 3. Regression results.

\begin{tabular}{cccccc}
\hline \multicolumn{7}{c}{ Coefficients } \\
& \multicolumn{2}{c}{$\begin{array}{c}\text { Unstandardized } \\
\text { Coefficients }\end{array}$} & $\begin{array}{c}\text { Standardized } \\
\text { Coefficients }\end{array}$ & & \\
\cline { 2 - 6 } & $\beta$ & Std. Error & Beta & t & Sig. \\
\cline { 2 - 6 }$($ Constant $)$ & 28.109 & 1.173 & & 23.960 & 0.000 \\
WFC & -0.238 & 0.030 & -0.385 & -7.935 & 0.000 \\
F-Statistics & & & 62.962 & & \\
$P$-Value & & & 0.000 & & \\
R Square & & & 0.148 & & \\
Adjusted R Square & & & 0.146 & & \\
\hline
\end{tabular}

Dependent Variable: Job Satisfaction, Predictors: (constant), Work-Family Conflict. 
Table 4. Disaggregated WFC and job satisfaction.

\begin{tabular}{cccccc}
\hline \multicolumn{6}{c}{ Coefficients } \\
& \multicolumn{1}{c}{$\begin{array}{c}\text { Unstandardized } \\
\text { Coefficients }\end{array}$} & $\begin{array}{c}\text { Standardized } \\
\text { Coefficients }\end{array}$ & & \\
& $\beta$ & Std. Error & Beta & t & Sig. \\
\cline { 2 - 4 } & 28.305 & 1.192 & & 23.749 & 0.000 \\
(Constant) & -0.210 & 0.073 & -0.165 & -2.890 & 0.004 \\
B-B & -0.216 & 0.079 & -0.155 & -2.714 & 0.007 \\
T-B & -0.319 & 0.088 & -0.189 & -3.624 & 0.000 \\
S-B & & & 21.245 & & \\
F-Statistics & & & 0.000 & & \\
$P$-Value & & & 0.150 & & \\
R Square & & & 0.143 & & \\
Adjusted R Square & & & & & \\
\hline
\end{tabular}

Dependent Variable: Job Satisfaction; Predictors: (Constant), Behaviour-Based, Time-Based, Strain-Based.

Table 5. Work-family conflict and gender.

\begin{tabular}{|c|c|c|c|c|c|}
\hline \multicolumn{6}{|c|}{ Coefficients } \\
\hline & \multicolumn{2}{|c|}{$\begin{array}{l}\text { Unstandardized } \\
\text { Coefficients }\end{array}$} & \multirow{2}{*}{$\begin{array}{c}\begin{array}{c}\text { Standardized } \\
\text { Coefficients }\end{array} \\
\text { Beta }\end{array}$} & \multirow[b]{2}{*}{$\mathrm{t}$} & \multirow[b]{2}{*}{ Sig. } \\
\hline & $\beta$ & Std. Error & & & \\
\hline (Constant) & 19.761 & 0.417 & & 47.433 & 0.000 \\
\hline Gender $=$ Female & -1.222 & 0.524 & -0.122 & -2.332 & 0.020 \\
\hline F-Statistics & & & 5.437 & & \\
\hline$P$-Value & & & 0.20 & & \\
\hline R Square & & & 0.015 & & \\
\hline Adjusted R Square & & & 0.012 & & \\
\hline
\end{tabular}

Dependent Variable: Work-Family Conflict; Predictors: (Constant), Gender = Female.

\section{Gender, Work-Family Conflict, and Job Satisfaction}

The study's last objective sought to investigate the moderating role of gender in the relationship between work-family conflict and job satisfaction.

Table 6 below shows the output from two regression models. In the model one, gender and WFC negatively and significantly affect the job satisfaction of doctors. All the independent variables were significant at $5 \%$ level. In model 2, the moderation of gender and WFC have a positive and insignificant effect on doctors' job satisfaction. Given the insignificant $p$-values ( $p$-value $>0.05$ ), the study fails to reject the hypothesis that H3: Gender does not moderate the relationship between work-family conflict and job satisfaction. 
Table 6. Gender, work-family conflict and job satisfaction.

\begin{tabular}{cccccc}
\hline & \multicolumn{5}{c}{ Coefficients } \\
& \multicolumn{2}{c}{$\begin{array}{c}\text { Unstandardized } \\
\text { Coefficients }\end{array}$} & $\begin{array}{c}\text { Standardized } \\
\text { Coefficients }\end{array}$ & & \\
\cline { 2 - 4 } Model 1 & $\boldsymbol{\beta}$ & Std. Error & Beta & $\mathbf{t}$ & Sig. \\
\cline { 2 - 4 } (Constant) & 30.446 & 1.427 & & 21.329 & 0.000 \\
WFC & -0.241 & 0.030 & -0.390 & -8.106 & 0.000 \\
Gender & -1.362 & 0.483 & -0.136 & -2.819 & 0.005 \\
\hline Model 2 & $\beta$ & Std. Error & Beta & $\mathbf{t}$ & Sig. \\
\hline (Constant) & 24.789 & 3.862 & & 6.418 & 0.000 \\
WFC & -0.097 & 0.098 & -0.157 & -0.983 & 0.326 \\
Gender & 2.106 & 2.316 & 0.212 & 0.909 & 0.364 \\
WFC ${ }^{*}$ Gender & -0.088 & 0.059 & -0.414 & -1.496 & 0.135 \\
\hline
\end{tabular}

R-Square Value: Model 1—0.167, Model 2—0.14.

\section{Discussion of Results}

The purpose of the research is to test the relationship between work-family conflict and job satisfaction with gender playing a moderating role in Ghanaian doctors' case of during the novel coronavirus pandemic. Many research studies have been conducted to test the relationship between work-family conflict and job satisfaction in different countries, with different demographic characteristics and various organizational sectors.

The contrast between this study and the other research is that this study investigates the link between the three multidimensionality (strain-based, time-based and behaviour-based) of work-family conflict (WFC) among doctors in Ghana.

The first finding from Table 3, suggests that WFC negatively impacts the job satisfaction of doctors. The study's finding is parallel to Deng, Yang, Wang, Yan and $\operatorname{Li}$ (2018), who similarly found a negative relationship between WFC and job satisfaction among doctors in China. A similar study by AlAzzam, AbuAlRub and Nazzal (2017), though focused on nurses also revealed a negative and significant relationship between work-family conflict and job satisfaction among Jordanian nurses. Furthermore, Lu et al. (2016), whose study explored job satisfaction among healthcare staff in Guangdong in China, is consistent with the current study. They discovered that work-family conflict negatively influenced job satisfaction Akram and Hassan (2013) showed a negative relationship between work-family conflict and job satisfaction.

The finding of this research can be explained as when doctors experience conflicting demands from work and family and are unable to balance this relationship, they tend to perform below their abilities, ultimately affecting the satisfaction they derive from the job. There are possibilities that the negative effect on job satisfaction may be due to several reasons. These reasons include lack of autonomy over their duties, lack of recognition, the working conditions surround- 
ing the job, and the number of working hours. This goes to agree with the Herzberg's two-factor theory. In regards to autonomy over work, Salvatore, Numerato, and Fattore (2018) established in their research that doctors recognize more with their hospitals when they have the opportunity to be flexible in their work and make decisions concerning their jobs. Based on the findings, the current study fails to reject the hypothesis $\mathrm{H} 1$ : Work-family conflict will negatively affect job satisfaction.

From Table 4, the second finding suggests that when doctors endure work-family conflicts emanating from behaviour, their job satisfaction is negatively impacted. Therefore, behaviour-based will negatively influence job satisfaction. The finding also suggests that doctors' job satisfaction is negatively impacted as and when there is disagreement in time demands between work and family. Dwelling on the results, the study fails to reject hypothesis H1b: Time-based (T-B) will negatively influence job satisfaction. Additionally, according to the study, strain-based conflict leads to a reduction in job satisfaction. This signals that when doctors transfer stress from work to home or vice versa, it negatively impacts their job satisfaction. Dwelling on the results, the study fails to reject the hypothesis H1c: Strain-based (S-B) will negatively influence job satisfaction. This study supports the findings of Deng et al. (2018). This research partly matched with the findings of Buonocore and Russo (2013), that stated that only time-based and strain-based conflicts have a negative effect on job satisfaction.

In Table 5, the finding a significant impact of gender (females) on the WFC. Females are negatively affected by WFC. Owing to the conventional gender-based division of labor, it is thought that females are more likely to have family expectations intrude on their job roles than men. Peculiar to Ghanaian society, a lot more is expected of a female in the home regarding family roles than men. Despite the persistence of gender expectations between males and females in the home, it is imperative to note the growing global perspective of non-discriminatory roles between males and females (Nohe, Meier, Sonntag, \& Michel, 2015), which gradually is penetrating the Ghanaian society. Cinamon and Rich (2002) provided evidence that WFC affects females less than men. Nonetheless, the findings contradict Ansari (2011), Mache, Bernburg, Vitzthurm, Groneburg, Klapp, and Danzer (2015), and Lyu and Fan (2020), who found no significant relationship between males and females in WFC.

Finally, from Table 6, a significant negative relationship was found between the independent variable (WFC and gender) and job satisfaction. This implies that job satisfaction decreases with work-family conflict on the one hand, and on the other hand, job satisfaction decreases among different gender. However, the result in model two shows that gender does not moderate the relationship between work-family conflict and job satisfaction. The relationship between work-family conflict and job satisfaction among doctors does not rely on the gender of the doctor.

Further, the current study matches with the findings of Kaur and Narula 
(2020), Deng et al. (2018), and Calvo-Salguero et al. (2010) studies are in accordance with the current study except that in their studies, gender plays a significant role in moderating work-family conflict and job satisfaction.

This research's overall findings are consistent with an earlier study by Rahman et al. (2018). They also reported that gender (male and female) does not moderate the relationships between work-family conflict and job satisfaction among university staff. This defies the assumptions of role theory and gender perspective theory of this current study.

\section{Conclusion \& Recommendations}

Work-family conflict is a never-ending challenge for many employees of all professions; however, managing the conflicts between them can lead to certain degree of employee satisfaction that the individual, institution and the country at large have to encounter. The findings of this research paper prove that WFC negatively impacts the job satisfaction of doctors. Thus, when doctors experience incompatible demands from work and family, and are unable to balance this relationship, they tend to perform below their abilities which ultimately affect the satisfaction they derive from the job. Behaviour-based (B-B) also negatively influences job satisfaction. Whereas, time-based (T-B) negatively influences job satisfaction.

Furthermore, Strain-based (S-B) negatively influences job satisfaction. The research recommended hospital management and policymakers consider ways of managing the autonomy, flexi-time, recognition, and working conditions of doctors working in either private or public hospitals to improve their job satisfaction during this pandemic and beyond. Since low job satisfaction of doctors is considered a personal crisis and has the tendency to affect communities and the nation at large appropriate measures. Strict implementations should be set to compensating doctors and their families when there is a global epidemic in the future. Further, policymakers and hospital management should initiate and organize more work-family conflict managements programs like symposia and lectures for doctors either quarterly, bi-annually, or annually.

\section{Limitation and Suggestion for Further Studies}

The paper is believed to add to the knowledge of work-family conflict and job satisfaction. However, there are some backdrops regarding the methodology. Firstly, the data collection employed the e-questionnaire that may influence the distribution approach leading to biases in data and response rate. This can be as a result of other electronic application or function easily distracting the respondent when filling the e-questionnaire leading to selection of random answers without properly reading to understand the question. Secondly, the sampling technique utilized has numerous disadvantages that can distort the sample of this study. The study employed both a probability (stratified) and non-probability (convenience and snowball) sampling technique. With the stratified sampling, 
the subject that fall in multiple groups have a higher tendency of being selected and therefore can cause a misrepresented sample. With the convenience and snowball sampling techniques, participants from the population do not have equal chance to be selected. This means the researcher may not know how well the participant selected can represent the population. This can hinder the true reflection of study.

Further research can be done by exploring other job satisfaction elements from working hours, recognition, autonomy, promotion, supervisors, and working condition.

\section{Conflicts of Interest}

The authors declare no conflicts of interest regarding the publication of this paper.

\section{References}

Adua, E., Frimpong, K., Li, X., \& Wang, W. (2017). Emerging Issues in Public Health: A Perspective on Ghana's Healthcare Expenditure, Policies and Outcomes. EPMA Journal, 8, 197-206. https://doi.org/10.1007/s13167-017-0109-3

Ajayi, D. T., Bello, S., \& Asuzu, M. C. (2018). Determinants of Job Satisfaction among Physicians in Public Hospitals in Calabar, Nigeria. Journal of Community Medicine and Primary Health Care, 30, 19-33.

Akram, A., \& Hassan, M. (2013). Impact of Work-Life Conflict on Job Satisfaction. Interdisciplinary Journal of Contemporary Research in Business, 5, 434-448.

AlAzzam, M., AbuAlRub, R. F., \& Nazzal, A. H. (2017). The Relationship between Work-Family Conflict and Job Satisfaction among Hospital Nurses. Nursing Forum, 52, 278-288. https://doi.org/10.1111/nuf.12199

Annor, F. (2016). Work Family Demands and Support: Examining Direct and Moderating Influences on Work-Family Conflict. Journal of Workplace Behavioral Health, 31, 87-103. https://doi.org/10.1080/15555240.2015.1119656

Ansari, S. A. (2011). Gender Difference: Work and Family Conflicts and Family-Work Conflicts. Pakistan Business Review, 13, 315-331.

Ary, D., Jacobs, L. C., Irvine, C. K. S., \& Walker, D. (2018). Introduction to Research in Education. Boston, MA: Cengage Learning.

Buonocore, F., \& Russo, M. (2013). Reducing the Effects of Work-Family Conflict on Job Satisfaction: The Kind of Commitment Matters. Human Resource Management Journal, 23, 91-108. https://doi.org/10.1111/j.1748-8583.2011.00187.x

Calvo-Salguero, A., Carrasco-González, A. M., \& De Lecea, J. M. S. M. (2010). Relationship between Work-Family Conflict and Job Satisfaction: The Moderating Effect of Gender and the Salience of Family and Work Roles. African Journal of Business Management, 4, 1247-1259.

Carlson, D. S., Kacmar, K. M., \& Williams, L. J. (2000). Construction and Initial Validation of a Multidimensional Measure of Work-Family Conflict. Journal of Vocational Behaviour, 56, 249-276. https://doi.org/10.1006/jvbe.1999.1713

Centers for Disease Control and Prevention (2020). Interim U.S. Guidance for Risk Assessment and Work Restrictions for Healthcare Personnel with Potential Exposure to Coronavirus Disease 2019 (COVID-19). Atlanta, GA: Centers for Disease Control and 
Prevention.

https://www.cdc.gov/coronavirus/2019-ncov/hcp/guidance-risk-assessment-hcp.html

Cinamon, R. G., \& Rich, Y. (2002). Gender Differences in the Importance of Work and Family Roles: Implications for Work-Family Conflict. Sex Roles, 47, 531-541. https://doi.org/10.1023/A:1022021804846

Coetzee, M., \& Stoltz, E. (2015). Employees' Satisfaction with Retention Factors: Exploring the Role of Career Adaptability. Journal of Vocational Behavior, 89, 83-91.

Dartey-Baah, K. (2015). Work-Family Conflict, Demographic Characteristics and Job Satisfaction among Ghanaian Corporate Leaders. International Journal of Business, 20, 292-307.

de Oliveira Vasconcelos Filho, P., de Souza, M. R., Elias, P. E. M., \& D’Ávila Viana, A. L. (2016). Physicians' Job Satisfaction and Motivation in a Public Academic Hospital. Human Resources for Health, 14, Article No. 75. https://doi.org/10.1186/s12960-016-0169-9

Deng, S., Yang, N., Li, S., Wang, W., Yan, H., \& Li, H. (2018). Doctors' Job Satisfaction and Its Relationships with Doctor-Patient Relationship and Work-Family Conflict in China: A Structural Equation Modeling. INQUIRY: The Journal of Health Care Organization, Provision, and Financing, 55, Article ID: 0046958018790831. https://doi.org/10.1177/0046958018790831

Drislane, F. W., Akpalu, A., \& Wegdam, H. H. J. (2014). The Medical System in Ghana. The Yale Journal of Biology and Medicine, 87, 321-326. https://www.researchgate.net/publication/265393597

Erdamar, G., \& Demirel, H. (2016). Job and Life Satisfaction of Teachers and the Conflicts They Experience at Work and at Home. Journal of Education and Training Studies, 4, 164-175. https://doi.org/10.11114/jets.v4i6.1502

Fu, J., Sun, W., Wang, Y., Yang, X., \& Wang, L. (2013). Improving Job Satisfaction of Chinese Doctors: The Positive Effects of Perceived Organizational Support and Psychological Capital. Public Health, 127, 946-951.

Greenhaus, J. H., \& Beutell, N. J. (1985). Sources of Conflict between Work and Family Roles. Academy of Management Review, 10, 76-88. https://doi.org/10.5465/amr.1985.4277352

Greenhaus, J. H., Ziegert, J. C., \& Allen, T. D. (2012). When Family-Supportive Supervision Matters: Relations between Multiple Sources of Support and Work-Family Balance. Journal of Vocational Behavior, 80, 266-275.

Hamid, R. A., \& Amin, S. M. (2014). Work-Family Conflict and Work-Family Enrichment and Their Consequences in Malaysia. Middle-East Journal of Scientific Research, 19, 729-733.

Jamadin, N., Mohamad, S., Syarkawi, Z., \& Noordin, F. (2015). Work-Family Conflict and Stress: Evidence from Malaysia. Journal of Economics, Business and Management, 3, 309-312. https://doi.org/10.7763/JOEBM.2015.V3.200

Kahn, R. L., Wolfe, D. M., Quinn, R. P., Snoek, J. D., \& Rosenthal, R. A. (1964). Organizational Stress: Studies in Role Conflict and Ambiguity. New York, NY: John Wiley \& Sons.

Katz, D., \& Kahn, R. L. (1978). The Social Psychology of Organizations (Vol. 2, p. 528). New York, NY: Wiley.

Kaur, H., \& Narula, S. (2020). Examine the Mediating Effect of Work-Life Balance on the Relationship between Work-Family Conflict and Job Satisfaction of Women Doctors. International Journal of Management (IJM), 11. 
Lent, R. W., Nota, L., Soresi, S., Ginevra, M. C., Duffy, R. D., \& Brown, S. D. (2011). Predicting the Job and Life Satisfaction of Italian Teachers: Test of a Social Cognitive Model. Journal of Vocational Behavior, 79, 91-97.

Lu, Y., Hu, X. M., Huang, X. L., Zhuang, X. D., Guo, P., Feng, L. F. et al. (2016). Job Satisfaction and Associated Factors among Healthcare Staff: A Cross-Sectional Study in Guangdong Province, China. BMJ Open, 6, e011388. https://doi.org/10.1136/bmjopen-2016-011388

Lyu, X., \& Fan, Y. (2020). Research on the Relationship of Work Family Conflict, Work Engagement and Job Crafting: A Gender Perspective. Current Psychology, 39, 1-11. https://doi.org/10.1007/s12144-020-00705-4

Mache, S., Bernburg, M., Vitzthum, K., Groneberg, D. A., Klapp, B. F., \& Danzer, G. (2015). Managing Work-Family Conflict in the Medical Profession: Working Conditions and Individual Resources as Related Factors. BMJ Open, 5, e006871. https://doi.org/10.1136/bmjopen-2014-006871

Malhotra, N. K., \& Peterson, M. (2006). Basic Marketing Research: A Decision-Making Approach. Hoboken, New Jersey: Prentice Hall.

Martins, O., Tukur, D., Danburam, A. \& Salwau, F. (2016). Job Satisfaction among Doctors and Nurses: A Case Study of Federal Medical Centre Yola, Nigeria. International Journal of Community Medicine and Public Health, 3, 1640-1647. https://doi.org/10.18203/2394-6040.ijcmph20161643

Matthews, R. A., Kath, L. M., \& Barnes-Farrell, J. L. (2010). A Short, Valid, Predictive Measure of Work-Family Conflict: Item Selection and Scale Validation. Journal of Occupational Health Psychology, 15, 75. https://doi.org/10.1037/a0017443

Nasurdin, A. M., Ahmad, N. H., \& Zainal, S. R. M. (2013). Comparing Work-Family Conflict and Facilitation among Male and Female Entrepreneurs in Malaysia. International Journal of Business and Society, 14, 149-159.

Nataša, M. Đ., Marion, K., Goran, K., \& Mirjana, R. (2010). Job Satisfaction among Medical Doctors in One of the Countries in Transition: Experience from Croatia Collegium Antropologicum, 34, 813-818.

Nawab, S., \& Iqbal, S. (2013). Impact of Work-Family Conflict on Job Satisfaction and Life Satisfaction. Journal of Basic and Applied Scientific Research, 3, 101-110.

Nohe, C., Meier, L. L., Sonntag, K., \& Michel, A. (2015). The Chicken or the Egg? A Meta-Analysis of Panel Studies of the Relationship between Work-Family Conflict and Strain. Journal of Applied Psychology, 100, 522-536. https://doi.org/10.1037/a0038012

Opoku Mensah, A., Amissah, E. F. \& Nsaful, A. A. (2018). Gender as a Moderator between Work-Family Conflict, Job and Family Satisfaction. International Journal of Arts and Humanities, 7, 1-12.

Owolabi, B. A. (2015). Effect of Work-Family Conflict and Job Satisfaction on Quality of Work Life. Advances in Social Sciences Research Journal, 2, 51-60. https://doi.org/10.14738/assrj.22.838

Pallant, J. (2010). SPSS Survival Manual: A Step by Step Guide to Data Analysis Using SPSS. Mainhead: Routledge.

Pfleiderer, B., Bortul, M., Palmisano, S., Rodde, S., \& Hasebrook, J. (2018). Improving Female Physician's Careers in Academic Medicine: Chances and Challenges. Best Practice and Research: Clinical Anaesthesiology, 32, 15-23.

Pitney, W. A., Mazerolle, S. M., \& Pagnotta, K. D. (2011). Work-Family Conflict among Athletic Trainers in the Secondary School Setting. Journal of Athletic Training, 46, 185-193. https://doi.org/10.4085/1062-6050-46.2.185 
Rahman, M. M., Ali, N. A., Mansor, Z. D., Jantan, A. H., Samuel, A. B., Alam, Md. K., \& Hosen, S. (2018). Work-Family Conflict and Job Satisfaction: The Moderating Effects of Gender. Academy of Strategic Management Journal, 17, 1-6.

Rui, H. (2017) The Influence of Doctor-Patient Relationship and Job Satisfaction on Physicians' Organizational Citizenship Behavior. Journal of Xi'an Jiaotong University (Social (Social Sciences), 37, 55-61.

Salvatore, D., Numerato, D., \& Fattore, G. (2018). Physicians' Professional Autonomy and Their Organizational Identification with Their Hospital. BMC Health Services Research, 18, Article No. 775. https://doi.org/10.1186/s12913-018-3582-Z

Ursachi, G., Horodnic, I. A., \& Zait A. (2015). How Reliable Are Measurement Scales? External Factors with Indirect Influence on Reliability Estimators. Procedia Economics and Finance, 20, 679-686. https://doi.org/10.1016/S2212-5671(15)00123-9

WHO, World Health Organization (2017). Health Empowerment and Economic Growth: An Evidence Base. https://www.who.int/hrh/resources/WHO-HLC-Report_web.pdf?ua=1

WHO, World Health Organization (2020). WHO Calls for Healthy Safe and Decent Working Conditions for All Health Workers Amidst COVID-19 Pandemic.

https://www.who.int/news-room/detail/28-04-2020-who-calls-for-healthy-safe-and-dec ent-working-conditions-for-all-health-workers-amidst-covid-19-pandemic

World Health Organization (2010). World Health Statistics 2010.

Yamane, T. (1967). Problems to Accompany "Statistics, an Introductory Analysis". Manhattan, NY: Harper \& Row.

Zotorvie, J. S. T., Kudo, M. B., \& Adade, T. C. (2017). A Survey of Factors that Influence the Level of Job Satisfaction and Turnover Intention of Professional Accountants in Ghana. International Journal of Academic Research in Business and Social Sciences, 7, 41-56. https://doi.org/10.6007/IJARBSS/v7-i10/3357 


\section{Appendix. Regression Results}

WFC and Job Satisfaction.

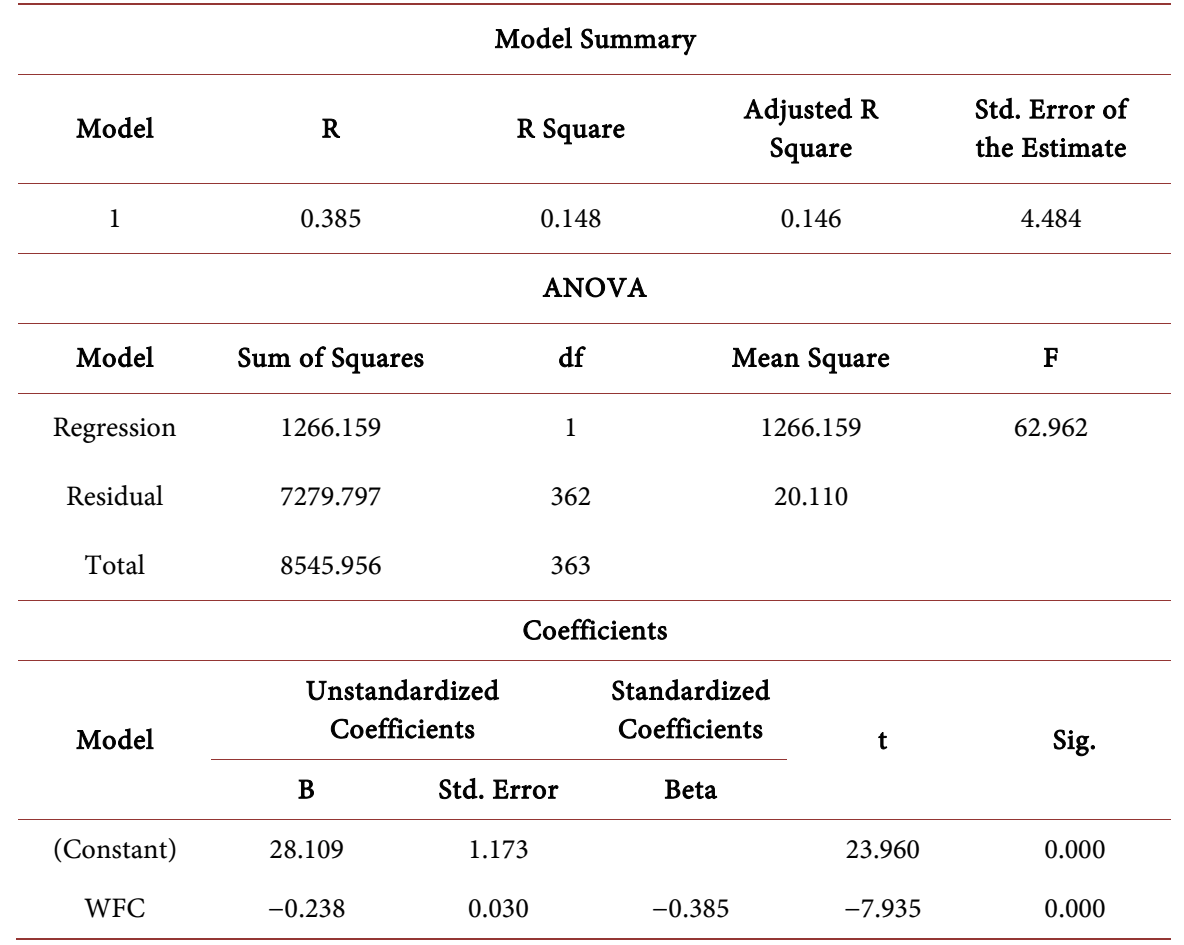

Dependent Variable: Job Satisfaction; Predictors: (Constant), WFC.

Disaggregated WFC and job satisfaction.

\begin{tabular}{|c|c|c|c|c|c|}
\hline \multicolumn{6}{|c|}{ Model Summary } \\
\hline Model & $\mathbf{R}$ & R Square & \multicolumn{2}{|c|}{$\begin{array}{l}\text { Adjusted R } \\
\text { Square }\end{array}$} & $\begin{array}{l}\text { Std. Error of the } \\
\text { Estimate }\end{array}$ \\
\hline 1 & 0.388 & 0.150 & \multicolumn{2}{|c|}{0.143} & 4.491 \\
\hline \multicolumn{6}{|c|}{ ANOVA } \\
\hline Model & Sum of Squares & df & \multicolumn{2}{|c|}{ Mean Square } & $\mathbf{F}$ \\
\hline Regression & 1285.397 & 3 & \multicolumn{2}{|c|}{428.466} & 21.245 \\
\hline Residual & 7260.559 & 360 & \multicolumn{2}{|c|}{20.168} & \\
\hline Total & 8545.956 & 363 & & & \\
\hline \multicolumn{6}{|c|}{ Coefficients } \\
\hline \multirow[t]{2}{*}{ Model } & \multicolumn{2}{|c|}{$\begin{array}{l}\text { Unstandardized } \\
\text { Coefficients }\end{array}$} & $\begin{array}{l}\text { Standardized } \\
\text { Coefficients }\end{array}$ & \multirow[t]{2}{*}{$\mathrm{t}$} & \multirow[t]{2}{*}{ Sig. } \\
\hline & B & Std. Error & Beta & & \\
\hline (Constant) & 28.305 & 1.192 & & 23.749 & 0.000 \\
\hline B-B & -0.210 & 0.073 & -0.165 & -2.890 & 0.004 \\
\hline $\mathrm{T}-\mathrm{B}$ & -0.216 & 0.079 & -0.155 & -2.714 & 0.007 \\
\hline S-B & -0.319 & 0.088 & -0.189 & -3.624 & 0.000 \\
\hline
\end{tabular}

Dependent Variable: Job Satisfaction; Predictors: (Constant), T-B, S-B, B-B. 
WFC and Gender.

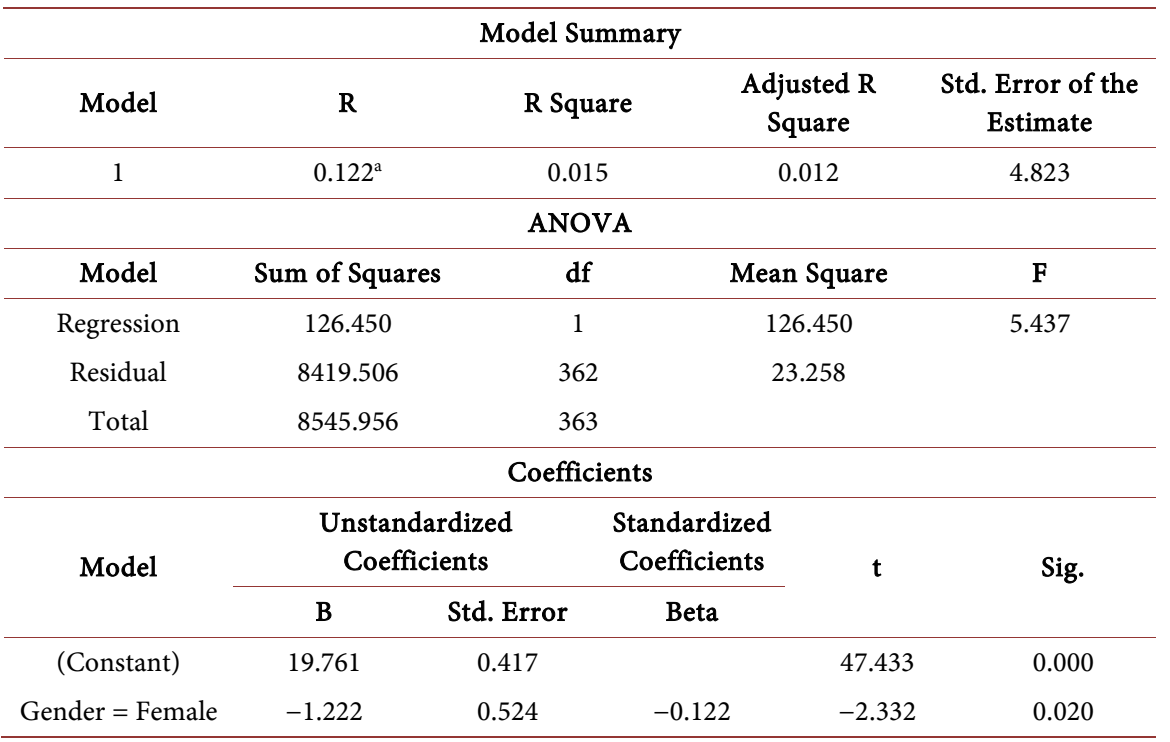

Dependent Variable: Job Satisfaction; Predictors: (Constant), Gender $=$ Female.

Gender, WFC and Job Satisfaction.

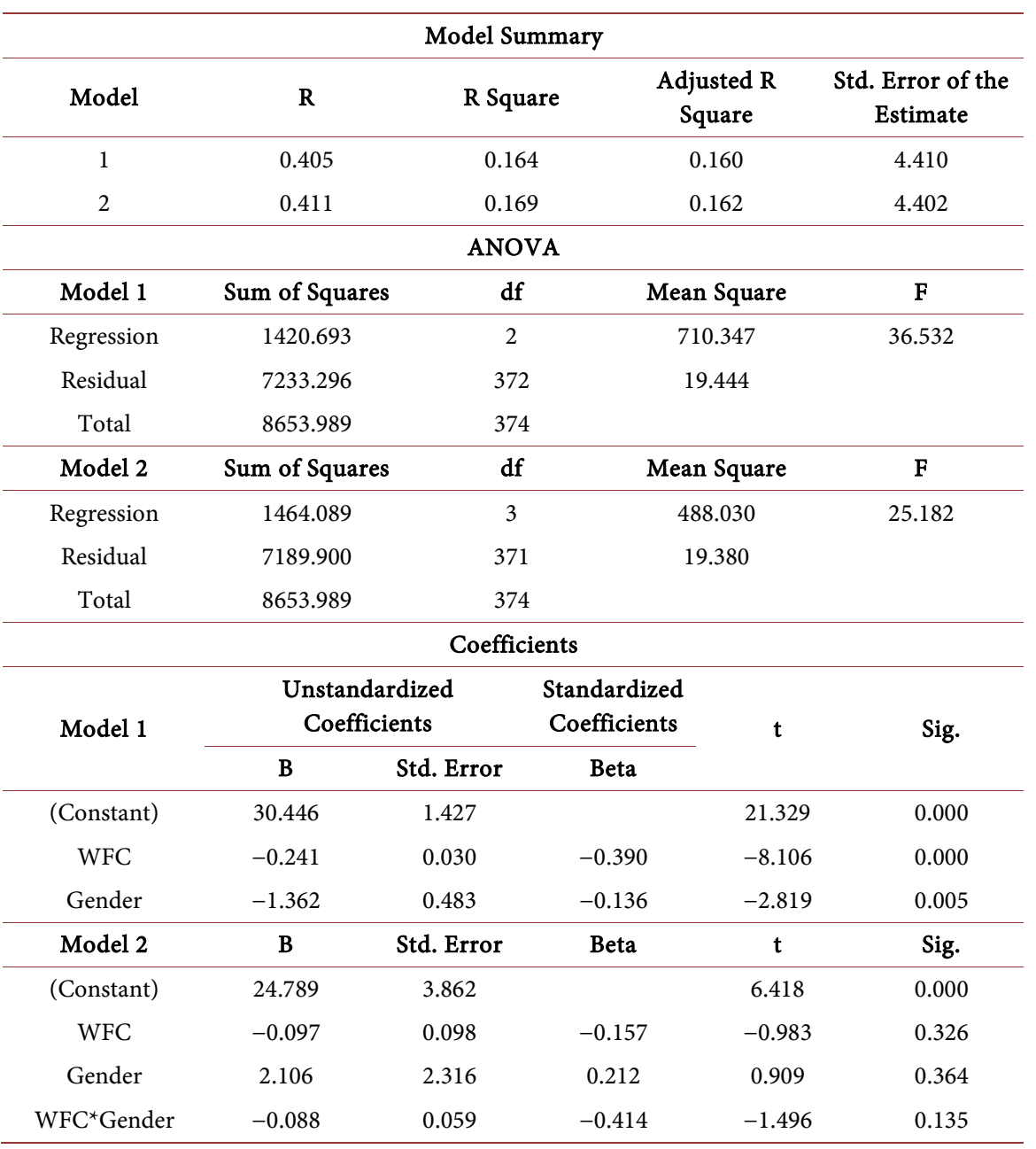

Dependent Variable: Job Satisfaction; Predictors: (Constant), WFC, Gender, WFC ${ }^{\star}$ Gender. 